4

\title{
A Thematic Analysis of Social Identity and Injury in CrossFit ${ }^{\circledR}$
}

\author{
Vista L. Beasley ${ }^{1}$, Rosie Arthur ${ }^{2}$, Robert C. Eklund ${ }^{3}$, Pete Coffee $^{4}$, \& Calum Arthur ${ }^{5}$ \\ ${ }^{1}$ Department of Kinesiology, Sport Studies, and Physical Education, State University of New \\ York-Brockport \\ ${ }^{2}$ School of Health and Life Sciences, University of the West of Scotland \\ ${ }^{3}$ College of Education, Florida State University \\ ${ }^{4}$ Faculty of Health Sciences and Sport, University of Stirling \\ ${ }^{5}$ Culture Development Advisor, United Kingdom Sport
}




\section{Abstract}

The purpose of this study was to explore the viability of the social identity approach as a theoretical framework for examining injury in the context of a group exercise program,

21 CrossFit@. Specifically, we sought to identify values of group exercise participants relevant to

22 overuse risk behaviors as well as participants' responses to criticisms about injury. Via thematic 23 analysis, observations of a CrossFit ${ }^{\circledR}$ setting $(\mathrm{N}=31)$ and interviews of members $(\mathrm{N}=14)$

24 yielded three social identity content (i.e., Being Hard Core, Achieving Results, Camaraderie).

25 Behaviors employed to enact these social identity content (e.g., engage in frequent, high-

26 intensity workouts; attend despite low-level pain; encourage others to continue despite pain;

27 withhold pain reports from group leaders) enabled members to obtain positive evaluations or 28 avert negative evaluations of group members yet also incurred higher overuse injury risk. We

29 also identified two prominent types of responses of CrossFit® members to criticisms about 30 injury in CrossFit ${ }^{\circledR}$ activity: Compare dimensions (e.g., how well members handled the injuries;

31 the effort they put into prevention; health benefits; strength gained) of the group which were

32 perceived as superior to other contexts, and denounce critics. These response types were 33 interpreted to reflect social creativity and polarization, respectively. Altogether, the findings

34 indicate that group-based psychological factors contribute to overuse injury, advancing previous

35 literature in which intra- and inter-personal factors were the primary focus. This study contributed to the literature by identifying theory-based injury risk factors in group exercise

37 contexts which may inform future injury-prevention interventions. 


\section{Thematic Analysis of Social Identity Constructs and Injury in CrossFit®}

Many harms are associated with injury incurred in physical activity contexts including

42

43 inability to work or attend school, financial costs of medical treatment, psychological distress, surgery, arthritis, and restricted mobility (Maffulli et al., 2010; Turner et al., 2002). To reduce these harms, researchers attempt to identify psychological factors which contribute to injury. The study of psychological factors of injury has been hampered in that, typically, researchers did not distinguish between acute and overuse injury though the two have different causal mechanisms and pain patterns (Ekenman et al., 2001; Johnson et al., 2014). Acute injuries stem from a single, identifiable event (e.g., foot broken when a person falls off a plyometric box) whereas the causal mechanisms of overuse injuries (e.g., shin splints) involve excessive intensity and frequency of movement, with no single, identifiable, causal event. At the onset of overuse injury, referred to as the early stages, pain reflects minor physical damage (e.g., tiny lesions in a tendon; Wilder \& Sethi, 2004). The pain is typically low-level, persistent, and/or intermittent, such that it is sometimes described as 'nagging' but does not impair function (e.g., able to run or squat despite pain; Launay, 2015; Russell \& Wiese-Bjornstal, 2015;

Tranaeus et al., 2014; Turner et al., 2002). Without functional impairment, sufferers in the early stages of overuse injury may not view themselves as injured, and they are able to continue engaging in the physical activity of their choice. The injury of those who rest or reduce effort may be resolved in the early stages because the body's repair response is sufficient for healing the damaged component (Wilder \& Sethi, 2004). But in many instances, those in the early stages of overuse injury continue with physical activity despite the pain (Turner et al., 2002). Those who continue physical activity despite the initial pain may exacerbate the damage (e.g., the lesions become larger) such that the injury's severity increases (Wilder \& Sethi, 2004). 
Taken together, behaviors that risk occurrence of overuse injury include exercising with

64 excessive intensity and/or frequency, and/or insufficient rest (American College of Sports Medicine, ACSM, 2014; Drum et al., 2017; Launay, 2015; Traneous et al., 2014; Wilder \& Sethi, 2004). Behaviors that risk increasing severity of overuse injury involve exercising and/or failure to rest despite initial injury pain. In this study, we refer to behaviors that increase risk of overuse injury occurrence, or severity of overuse injury, collectively as overuse risk behaviors. One focus of the current study is to examine psychological factors which influence engagement in these overuse risk behaviors.

In recent years, research involved initial attempts to identify psychological factors specific to overuse injury of athletes involved in sports (e.g., runners, floorball players, rhythmic gymnasts; Cavallerio et al., 2016; Russell \& Wiese-Bjornstal, 2015; Tranaeus et al., 2014).

Some of the psychological factors identified in these studies were specific to competitive, sport contexts (e.g., desire to complete a marathon in three hours; pressure from coaches to train despite pain). It would seem that psychological factors relevant to injury in exercise contexts differ from those of sport contexts, given the absence of win/loss outcomes and coaches whose reputations and livelihoods rely on those outcomes. To our knowledge, research specific to overuse injury psychological factors has not been conducted in exercise contexts. Additionally, the psychological factors pertaining to overuse injuries of athletes were of an intra-personal (e.g., Type A personality, Ekenman et al., 2001) and inter-personal (e.g., relationship between athletes and medical personnel; Turner et al., 2002) nature. Little is known about group-based psychological factors in relation to overuse injury in sport or exercise contexts.

One theoretical framework that could enhance the study of group-based exercise contexts is the social identity approach. This approach is used in the study of groups (e.g., a sports team, 
an exercise program/class) whose members perceive themselves to be similar to each other in meaningful ways through shared values, beliefs, attitudes, and/or behaviors (Jetten et al., 2017). Social identity content refers to shared values that underpin group membership (Evans et al., 2016; Hogg \& Reid, 2006; Jetten et al., 2017; Livingstone \& McCafferty, 2015; Slater et al., 2014). For example, let us suppose that members of a running group say "pushing ourselves to the limit is what we're about" whereas members of an exercise class say "it's important to us to exercise safely". Such values impact subsequent behaviors that are either endorsed or rejected by members of the group. Members of the running group who continue running despite pain to achieve the absolute limits of their performance capability might be considered exemplar (prototypical) members of their group. Conversely, this same type of behavior may be frowned upon by members of the exercise class who value exercising safely. Evidence for the impact of social identity content on behaviors has been demonstrated in the literature. For example, when alcoholic consumption is viewed as a defining value (a negative social identity content) of a group of university students, binge drinking may occur (Livingstone \& McCafferty, 2015). In this way - and similar to the social identity content underpinning our running group examplesocial identities may become a curse that threatens and potentially harms group members' health and well-being (Jetten et al., 2017). Building on this, we proposed that negative social identity content may influence engagement in injury-risk behaviors in group exercise contexts.

To examine psychological factors specific to injury in group exercise contexts, we chose the group exercise context of CrossFit ${ }^{\circledR}$. More than 15,000 gyms around the world are affiliates of the CrossFit ${ }^{\circledR}$ brand (CrossFit ${ }^{\circledR}$, n.d.). While some members may opt to engage in CrossFit ${ }^{\circledR}$ competitions, the focus of this study is the group exercise component of the program. CrossFit ${ }^{\circledR}$ is one of the few exercise contexts known to us in which injury rates, and specifically overuse 
injury occurrence, have been studied. In these studies, $19 \%$ to $73.5 \%$ of CrossFit@ members reported injury, and $16 \%$ to $35.5 \%$ of the injuries were designated as overuse injury or chronic onset (Klimek et al, 2018; Montalvo et al., 2017; Weisenthal et al., 2014). These injury rates were on par with that of sports participants (e.g., powerlifters, elite gymnasts; Montalvo et al., 2017). Some critics of Crossfit $®$ have expressed concern about the amount of involved injury risk (Diamond, 2015). In contrast, CrossFit $®$ members find that the modalities of the CrossFit ${ }^{\circledR}$ context, along with the atmosphere and connectedness, contribute to physical activity adherence (Bailey et al., 2017). As such, CrossFit ${ }^{\circledR}$ members may perceive the criticisms of the injury rate of CrossFit@ to be threatening to their group. In other words, within the social identity approach, social threats involve negative evaluations of a social identity group such that members, feeling that a source of positive self-esteem is threatened, may be incited to defend their group (Brown \& Ross, 1982; Evans et al., 2016).

The overarching purpose of this study was to apply the social identity approach to the exploration of the psychological factors related to injury in a CrossFit ${ }^{\circledR}$ exercise context. While the literature review suggested numerous avenues of research, we narrowed our focus to these two research questions: (1) What are the values within a CrossFit@ group, and how might they be relevant to overuse risk behaviors? (2) How do CrossFit ${ }^{\circledR}$ members respond to criticisms about the occurrence of injury in CrossFit ${ }^{\circledR}$ activity?

\section{Method}

\section{Philosophical Perspective and Design}

This project was shaped by the pragmatic paradigm in which research can be perceived as a means for gaining knowledge about a problem in the human experience (e.g., injury; Kaushik \& Walsh, 2019; Morgan, 2014). Within this paradigm, an alignment between methods and 
132 research questions, rather than philosophical concerns (e.g., nature of reality and knowledge), is

133 a focus. Thus, researchers are called upon to consider the information and beliefs that informed

134 their methodological choices, weigh the consequences, and adjust accordingly until they form a

135 warranted belief that the method is suited for answering the research questions.

The first research question required a means for identifying values of a CrossFit@ group.

137 In previous studies, the values of groups - to infer social identity content - were pre-identified

138 by researchers, or statements of group leaders were used to identify meaningful social identity

139 content (Barker et al., 2014; Livingstone \& McCafferty, 2015; Slater et al., 2014). Given the

140 above-noted conflict between views of CrossFit ${ }^{\circledR}$ members and critics, we perceived it to be

141 critical that CrossFit® members themselves contribute to identification of the group's values.

142 Therefore, we adopted the recommendation of Evans et al. (2016) by employing qualitative

143 methods to elicit the group's social identity content. In line with the pragmatic paradigm, we

144 also opted to use two methods - observations and interviews - as multiple methods enhance the

145 ability to gain knowledge (Morgan, 2014). Observations are also relevant to social identity

146 content because they reveal which behaviors are used to enact the values of a social identity

147 group (Hogg \& Reid, 2006). The use of interviews is also aligned with the pragmatic paradigm

148 in that people are not expected to have identical perceptions because they do not have identical

149 experiences (Kaushik \& Walsh, 2019). However, there are degrees of shared experiences

150 between any two people that lead to degrees of shared beliefs which can be captured to some

151 degree via interviews.

\section{Sampling and Participants}

Participants in this study were members of a CrossFit@ gym in a city in the southeastern

154 United States. The choice to limit this study to one gym was based in part on the knowledge, as 
stated by an owner of this gym, that almost all gym members engaged in CrossFit@ as an exercise activity. Only a handful engaged in the competitive component of the CrossFit ${ }^{\circledR}$ program. Additionally, there is evidence that there is wide variation between CrossFit ${ }^{\circ}$ gyms (e.g., management practices, injury rates) though they share the same brand name (Weisenthal et al., 2014). Given these disparities between gyms, social identity content may also differ between gyms; thus, we sought participants with membership at the same gym. Convenience sampling was primarily used for both observations and interviews in order to be non-invasive and emphasize anonymity. This decision reflected ethical consideration to avoid negatively affecting the gym's business activity or the relationships between owners and members.

For observations, participants consisted of members who entered the gym during the times when the first author conducted observations. Sex, role (e.g., trainer, member), physical description, and behaviors were the only characteristics of observed members recorded. To increase the number of members and types of behaviors observed, observations of 29 workouts were made at multiple times of day (i.e., morning, $n=7$; afternoon, $n=10$; evening, $n=12$ ). To prevent observations from being biased by advance knowledge, participants were not notified in advance about which workout periods would be observed. Also observed were one intra-gym competition and one mandatory induction course for new members. Observations included 85 participants (44 male members, 32 female members, 6 male trainers, 1 female trainer, 2 gym owners). For interviews, 10 members volunteered to be interviewed. Two members were recruited when they initiated conversation with the first author, at which time the first author invited them to participate as interviewees. Snowball sampling was also used in that interviewees were asked to recommend other members for interviews. The first author approached two recommended members, providing contact information in case they were willing 
178 to be interviewed. Within these strategies, we aimed to interview members who possessed 179 attributes which were pertinent to overuse injury. Attributes included membership duration, 180 wearing physical appliances (e.g., knee brace), prior overuse injury, an athletic background, sex, 181 and age. Most interviewees represented multiple attributes (e.g., an older member with no 182 athletic background wore a knee brace). The 14 interviewees encompassed all of these 183 attributes, consisting of 8 male members, 4 female members, 1 male trainer, and 1 male gym 184 owner, ages $20-52$ years $(M=34.43)$. The mean duration of interviews was 75 minutes, 21 185 seconds. Table 1 contains more details about interviewees.

[Table 1 near here]

\section{Data Collection}

Prior to data collection, five pilot interviews and three pilot observations were conducted.

A high quantity of data was rendered from each pilot interview and observation, highlighting the need to narrow the scope of the study. Therefore, the research questions were limited to social identity content and criticisms of CrossFit@ rather than exploring more aspects. Further, we

192 learned that some members perceive researchers conducting research about injury in CrossFit ${ }^{\circledR}$ 193 settings to be critics, evoking a defensive posture. After piloting, the interview guide was 194 adjusted such that explicit questions about pain and injury were last. In this way, we were 195 careful to avoid asking leading questions about injury. Consequently, we found that interviewees brought up the topics of pain and injury prior to being explicitly asked about these

197 topics. Pilot interviews also revealed that members were not familiar with overuse injury origins 198 or pain patterns which limited their ability to respond to explicit questions about overuse injury. 199 This demonstrated the need for researchers to identify participants' descriptions of behaviors as 200 overuse risk behaviors when participants did not name them as such. 
The final interview guide (online Appendix A) consisted of rapport-building and biographical questions, followed by questions pertaining to social identity constructs, criticisms of CrossFit ${ }^{\circledR}$, and then explicit questions about pain and injury. The interview questions 204 addressed four aspects of social identity content. Descriptions of the four aspects, along with sample questions, are: (1) In-group homogeneity (Turner et al., 1987): Perceived similarities of 206 group members (e.g., "What, if anything, do you have in common with other CrossFitters?"); (2) 207 Positive distinctiveness (Haslam et al., 2011): Attributes of a group which serve as reasons for 208 members to join and/or perceive the group to be distinct from and, typically, preferred to other 209 groups (e.g., "What do you like about CrossFit@?"; "How is that different from what you liked about other exercise activity you've been involved in?”); (3) Prototypicality (Haslam et al.,

211 2011): Attributes possessed by prototypical, highly-regarded members (e.g., "Who at your

212 CrossFit ${ }^{\circledR}$ gym impresses you most? Please describe them.”); and (4) In-group status (Turner et 213 al., 1987): Attributes for which members can be perceived positively by other members (e.g., If 214 you want to be perceived favorably by other CrossFitters, what do you need to do?). Questions 215 in the interview guide also addressed our second research question by eliciting participants' 216 responses to criticisms of CrossFit ${ }^{\circledR}$ (e.g., "What, if any, criticisms have you heard about 217 CrossFitters?”).

218 After receiving approval from an institutional ethics committee, informed consent was 219 sought from the gym owner. Given the public nature of the venue, the gym owner was identified 220 as the "gatekeeper" who was responsible for providing access and giving informed consent for 221 observations in these settings. Two weeks before observations started, flyers at the gyms and 222 posts on the gym's social media were used to notify members about the study. These materials 223 included a description of the study and informed members that a researcher would be observing 
224 members in the gym as part of the study. Members were invited to ask questions or express

225 concerns to the gym staff, owner, researchers, or ethics committee prior to start of observations.

226 No members expressed concerns. The first author conducted observations over a two-month

227 period. During observations, the first author jotted handwritten notes. In these notes, members

228 were given an identifier code, constructed to indicate sex $(\mathrm{F}=$ female, $\mathrm{M}=$ male $)$, role $(\mathrm{M}=$

229 member, $\mathrm{T}=$ trainer, $\mathrm{GO}=$ gym owner), and the chronological order in which the researcher

230 observed the participant (e.g., MM1 was the first male member observed). After each

231 observation, the first author typed the handwritten notes to form field notes $(\mathrm{N}=106$ single-

232 spaced pages). Two weeks after the start of observations, flyers and posts recruiting

233 interviewees were displayed. The choice to start interviews after a short time of observations

234 was deliberate, as it was intended to enable the researcher to ask questions about what was

235 observed. Interviewees selected the locations (e.g., coffee shops) for interviews and provided

236 informed consent. Interviews were conducted by the first author, audio-recorded, and

237 transcribed verbatim.

\section{Data Analyses and Saturation}

239 Data were analyzed using NVivo software (v. 11). To start, the first author reviewed all

240 interview transcripts and field notes. Transcripts were sent to interviewees who were invited to

241 provide comments, clarifications, or changes in views. This was intended to check transcript

242 accuracy and generate additional data and insight, but interviewees did not provide new

243 information. Next, an inductive approach was used for a thematic analysis (Braun \& Clarke,

244 2006). The analysis consisted of descriptive coding used to identify simple, lower-order codes

245 across interviews followed by coding of observation data. Then, higher-order themes were

246 developed to represent relationships between lower-order codes across interviews and 
247 observations. A focus of these steps was on internal homogeneity (i.e., each code/theme had

248 adequate evidence) and external homogeneity (i.e., no overlap between evidence supporting two

249 codes/themes). A final step, as employed by other sport/exercise psychology researchers (e.g.,

250 Chan et al., 2014; Long et al., 2014; Hings et al., 2020), involved relating the higher-order

251 themes to the research questions and theoretical constructs. For the first research question, social

252 identity content were determined by higher-order themes which spanned all four social identity

253 constructs (i.e., positive distinctiveness; in-group status; prototypicality; in-group homogeneity).

254 Behaviors used to enact each social identity content were examined for indicators of overuse risk

255 behaviors (e.g., a member continued to participate in workouts despite low-level injury pain; a

256 member exercised with excessive intensity and/or frequency, and/or insufficient rest). For the

257 second research question, themes derived from participants' responses to criticisms of the injury

258 occurrence in CrossFit ${ }^{\circledR}$ were examined. The first author provided research team members with

259 sample texts and themes, along with memos in which data were interpreted through a social

260 identity lens. Iterative discussions and reviews occurred. The aims of these interactions were to

261 determine whether the interpretations were supported by the data (i.e., warranted assertions) and

262 the research questions were answered, aims that are emphasized within the pragmatic paradigm

263 (Kaushik \& Walsh, 2019; Morgan, 2014).

264 Throughout data collection and analysis, data saturation was considered to determine

265 whether additional interviews or observations were needed. We note that guidance regarding

266 data saturation and sample size typically pertains to analysis of one type of data such that little

267 guidance is given in assessing data saturation from multiple methods (i.e., observations and

268 interviews). Thus, we opted to assess data saturation after higher-order themes were identified.

269 In accordance with Hennick et al. (2014), saturation was reached when no new salient codes (i.e., 
270 pertaining to injury or social identity constructs) were generated. Additionally, we considered

271 the guidance of Morse (2020) indicating that smaller sample sizes are appropriate when sampling

272 a cohesive group, addressing narrow research questions, and the scope of the project is narrow.

273 Given our sample consisted of members of one CrossFit ${ }^{\circledR}$ gym in a two-month period, addresses

274 two specific research questions, and focused on one phenomenon, injury, the sample size of 14

275 interviews and 31 observations was commensurate with this guidance.

276 Methodological Rigor

Amongst pragmatist researchers, a standard to consider in terms of rigor is whether the

278 method produced desired and useful results such that (1) knowledge was gained; (2) research

279 questions were answered; and (3) interpretations are defensible, consisting of warranted

280 assertions (Kaushik \& Walsh, 2019). To meet these standards, research team members consisted

281 of scholars with expertise in injury, social identity, and exercise psychology who supervised the

282 first author, a graduate student at the time of the study, in the design, data collection, and

283 analysis. Their expertise enabled them to assess data and interpretations to determine whether

284 knowledge was gained in terms of advancing the extant literature in these areas. Additionally, 285 they served as critical friends to determine whether interpretations were defensible and as peer 286 reviewers to determine whether research questions were answered.

287 Rigor can also be assessed specific to the methods used. Given our use of qualitative 288 methods, we considered markers of quality of qualitative research, including criteria (italicized 289 below) summarized by Tracy (2010). We believed the topic to be worthy given the harms of 290 injury. To achieve rich rigor, we considered theoretical constructs in relation to the topic; 291 captured extensive data from multiple sources; and presented original text samples such that 292 readers could determine plausibility of our interpretations. To contribute to transparency, we 
293 provided details regarding our rationale for our choices (e.g., why we placed explicit questions

294 about injury last in the interview guide). Regarding self-reflexivity, we acknowledge the first 295 author was a member of this CrossFit@ gym for a five-month period approximately two years

296 prior to conduct of this study. This membership resulted in a positive preconception of

297 CrossFit ${ }^{\circledR}$ as a program which enabled people to gain the physical and psychological benefits of 298 physical activity. Thus, it was of particular value to include research team members who had no 299 relationship with the gym. Though the first author's five-month membership at the gym was a 300 potential source of bias, prior knowledge of the gym's practices contributed to the study's 301 credibility. Credibility was also enhanced by ensuring findings included thick description (e.g., 302 concrete details) and dissenting views amongst participants. To enhance resonance, details of 303 participants' words and behaviors were presented such that readers with no exposure to 304 CrossFit ${ }^{\circledR}$ gyms or CrossFit ${ }^{\circledR}$ lexicon could understand within their own personal life 305 experiences, thus contributing to naturalistic generalizability. The study represents a significant 306 contribution, in that we give voice to a population who may be criticized by others, and we 307 advance the study of injury in exercise contexts. Ethical considerations included efforts to 308 ensure anonymity such that participants' characteristics were not detailed to a degree that would 309 enable them to be recognized by other members, trainers, or gym owners. Finally, we attempted 310 to achieve meaningful coherence by showing how our choices were supported by the pragmatic 311 paradigm and by focusing on psychological factors unified by theory.

\section{Results}

In this section, the findings are divided into two parts reflecting the two research

314 questions: (a) group values relevant to overuse risk behaviors, and (b) responses to criticisms 
about the occurrence of injury in CrossFit ${ }^{\circledR}$ activity. Verbatim quotations from participants are within quotation marks.

\section{Group Values Relevant to Overuse Risk Behaviors}

Three values, represented by in vivo terms, were found to be relevant to overuse risk behaviors: Being Hard Core, Achieving Results, and Camaraderie. For each value, we describe (a) characteristics of the value, (b) how the values are enacted, (c) reasons for enacting the values in that way, and/or (d) how the values were relevant to overuse risk behaviors.

Being Hard Core. "Hard core-ness" was a term used by MM44 to describe the type of people who do CrossFit ${ }^{\circledR}$, which tended to be people who "enjoy intense workouts" and were "not afraid of discomfort". According to MM42, "People that voluntarily join CrossFit ${ }^{\circ}$ are people that want to sort of push themselves more or exert more effort.” MM34 liked CrossFit ${ }^{\circledR}$ because "it's something that pushes me really to the limit of what I can tolerate". He previously experienced that feeling in cycling, but "still never anything quite as much as something that is really a great CrossFit ${ }^{\circledR}$ session”. One way that members enacted the value for being hard core was by completing high-intensity, challenging workouts. A reason for completing high-intensity workouts is explained by MM43 who said that members earn a "badge of honor". "Like, 'I'm kind of a tough guy because I can do these CrossFit ${ }^{\circledR}$ workouts, and I push myself””.

Completing the difficult workouts enhanced FM31's beliefs about her abilities:

I would look at the workout, and I would be like, 'There's no way. Like, this is way too hard. Is GO1 out of his mind?' I was like, 'I'm not an athlete. I can't', you know, and, and I would finish it...I would be laying on the floor, about to pass out. 'I just did that. I really completed that workout'... and I was like, 'I can't believe it.'... That's what sucked me in, was I started to see I was doing things that I didn't think I could do. (FM31)

A second way in which members enacted the value of being hard core was by attending regularly despite the intensity or other difficulty which, when excessive, is an overuse risk 
behavior. Members indicated that consistency in attendance was enacted uniquely in relation to CrossFit ${ }^{\circledR}$ participation, as shown by MM32:

As an adult, I got into golf, a little bit of basketball here and there with friends, and then off and on with the gym, very sporadically. Really, CrossFit ${ }^{\circledR}$ has been the first time I was almost religious about it in terms of truly dedicated, five days a week. Obviously now it's been 20 months straight.

One reason may be because CrossFit ${ }^{\circledR}$ members who attended regularly were positively evaluated by other members. As MM32 stated, "Pretty much everyone that comes there on a regular basis, doesn't mean daily, but on a regular basis, I have a great affinity for and admiration for." Admiration for attendance despite difficulty was displayed in an exchange in which FM12 told FM14 about having a sore throat for the previous two days. FM14 responded, "Yeah, but you're here", in a tone indicative of praise. To FM24, members were hard core in that they attended "no matter what": "We wake up the next day and come to it, no matter how sore we are, no matter what we feel like, like oh, 'I don't want to go', we still show up”. FM24's enactment of the hard core value in this way resulted in the overuse risk behavior of continuing exercising in the early stages of injury:

I kind of tweaked my back, and I was like 'Oh I'm fine. It's probably like just a little muscle spasm strain, no big deal.' That happened like November, and I kept going until February to the point where I couldn't sit. I couldn't sleep. I was crying. I popped Advil ${ }^{\circledR}$ every few hours.

In one instance, the first author observed that being hard core in terms of attending "no matter what” affected CrossFit ${ }^{\circledR}$ members' amount of rest in between workouts. On a morning in which the gym was not open due to a scheduling glitch, members (e.g., MM20, FM12, MM39) who usually attended the 5:30 a.m. sessions arrived, but, seeing the gym was closed, left. Later that day, these members attended the 5:30 p.m. CrossFit ${ }^{\circledR}$ class. The next day, they attended the CrossFit ${ }^{\circledR}$ workout at their normal 5:30 a.m. class time. Therefore, they attended two, high- 
intensity CrossFit ${ }^{\circledR}$ workouts in less than 12 hours rather than opting to miss a workout, yet insufficient rest is an overuse risk behavior.

However, it was also observed that some members adjusted their attendance and intensity at times. For examples, MM32 typically attended despite pain but did not attend "no matter what". "I definitely come with aches and pains every day, don't get me wrong", but "one time where I really felt like I hurt myself, I wasn't going to go in for a few days through that.” When FM31 struggled with an illness, she did not attend CrossFit ${ }^{\circledR}$ for a couple of weeks. During FM31's absence, GO2 messaged her, "When are you going to be here? I miss you". FM31 perceived these actions by GO2 to be "really sweet". When FM31 returned to CrossFit $®$ after the absence, FM31 did the warm-up with the rest of the members, but then did a workout that GO2 designed for FM31. The workout "was something to get me sweating a little bit, but it wasn't too intense because I had been sick, and I didn't want to push myself too far." GO2 told FM31, "Any time you want to come in and you've been sick or something like that and you want the trainer to do that [tailor a workout to needs], they'll do that...because I'd rather you show up than not show up." GO1 explained the gym owners' proactive stance towards encouraging members' attendance: If CrossFit@ members attended workouts often, they achieved desired results which, per the next section, was a basis for members continuing as paying gym members. A third way in which members enacted being hard core was by withholding pain reports from trainers. That is, they did not inform the trainers or others about pain. Instead, they continued to exercise despite pain which is an overuse risk behavior. One reason for doing so was an aversion to being perceived negatively, as shown by MM43: "especially when I first started, there was a lot of pulling shoulders and things like that...like, 'Okay, I probably shouldn't do this movement because my shoulder's still a little sore,' but I'm like, 'I don't want to 
392 be a wimp and complain again.' It's like, 'All right. Just try to do it'”. As stated by FM2, people who complained during workouts could be described as "annoying". MM43 indicated positive evaluations could be obtained "Even if you're the slowest person there, if people see...you're not whining about, you know, this or that exercise". Fear of negative evaluation inhibited MM44's pain report as well. When he felt shoulder pain, he at first did not tell trainers for fear he would be perceived as "sandbagging", but when the shoulder pain was so bad that he could not do more, he finally told a trainer. The trainer reacted to the pain report by being upset with MM44 for not being open about what was going on. The trainer also let other trainers know about MM44's pain which resulted in them devising ways to help MM44 modify workouts:

401

402

403

404

405

406

407
I hadn't seen MT1 in weeks, and I was doing squats, and he walked over and said "Hey man how is your shoulder?". Just out of the blue. I hadn't talked to him about it. It was genuine concern there, probably because the workout that day had a lot overhead stuff, and he wanted to get his gears going on what might need to be scaled or addressed. He was genuinely understanding, and we talked about what I've been doing to fix it, and he gave me more advice on how to strengthen those rotator cuff muscles.

After MT1 asked MM44 about the pain, MM44 became more comfortable reporting pain.

"Now, during the warm-ups, I will say 'MT6, hey, my shoulder is not feeling so hot today"'.

Likewise, other members tended not to report pain until trainers directly solicited a pain report.

In one workout, a female member said, "My arms really hurt." After hearing her, MT1 asked,

"Who else is in this boat? The 'can't do push-ups' boat?" Two female members raised their

hands. He gave them a different activity to do. Of note, the members did not tell MT1 about the pain until after he asked, suggesting they would have continued with the activity despite pain if he had not solicited that information. Likewise, MM19 did not discuss pain he was having until MT4 asked him, "How's the back?” After that, MT4 expressed that he himself was having pain too, after which MM19 added "Hips destroyed", referring to other pain he was experiencing. 
418

MM19 appeared comfortable telling MT4 about his pain only after MT4 asked him, and after MT4 expressed that he too had pain.

Achieving Results. CrossFit ${ }^{\circledR}$ members valued achieving results in the form of improvements in performance (e.g., amount of weight lifted) and/or appearance (e.g., body weight). Some interviewees indicated that results from CrossFit@ participation were better than results obtained via other physical activity contexts. Per FM31: "I didn't see the results at those group [name of traditional gym] classes that I saw the results at CrossFit®”. For MM30, who had been a professional athlete, the performance results he gained from CrossFit ${ }^{\circledR}$ were better than those he gained during his training as professional athlete: "In hindsight, I wish I'd done CrossFit ${ }^{\circledR}$ supplementary to my training...today, I hit the highest numbers I've ever hit in terms of squat, in terms of deadlift, numbers I wasn't even coming close to [before CrossFit ${ }^{\circ}$." The varied nature of CrossFit ${ }^{\circledR}$ workouts provided all members, not just the high-caliber athletes, with opportunities to perform better than other members. MM29 described himself, saying "I'm at the end of the pack in terms of results or, you know, where I finish," but "I'm good at box jumps I guess. That's about really all I can do to impress people athletically.” Similarly, FM12 said, "I'm certainly not the, like, weight-wise the strongest person at the gym, but... I was able to do dips without bands fairly quickly...I mean not that there's a hundred of them, but...people were blown away by that." By performing well at one specific activity, these members were able to garner positive evaluations of group members.

Members also emphasized appearance results, as shown by MM42: "I was a very skinny person, so I like the fact I gained 30 pounds in a year and a half [after starting CrossFitß].” MM29 sought appearance-related results "in terms of the eyeball test, how I look." Before he started CrossFit ${ }^{\circledR}$, “people would be like, 'So, are you working out?' And I'd be like, 'Yes, I've 
441 been working out religiously. Is this not apparent?'. And they'd be like, 'No"'. Discouraged, he

442 had ceased participation in previous exercise programs. During his few months of CrossFit@

443 attendance, he increased his number of pull-ups from zero to six. Despite these performance

444 results, he expressed his intent to quit CrossFit@ if he did not experience visible, appearance

445 results. FM24, too, was initially interested in appearance results, participating in CrossFit@ "just

446 to lose the weight and to keep it off." Her focus eventually changed from appearance to

447 performance as she started to "get better, to take it more serious, instead of just like a form of

448 weight management." FM12 loved "seeing the changes in my body", such as muscular

449 striations. Due to the strength she gained via CrossFit ${ }^{\circledR}$ participation, she was "able to lift

450 things, and not have to ask for help...I used to always have to ask someone for help, open jars,

451 stuff like that...I just feel...more confident."

452

453

454

455

456

457

458

459

460

461

462

463

464

465

466

467

468
A key feature of results in CrossFit ${ }^{\circledR}$ is that they could be achieved quickly. As FM31

said, "I've tried different things [exercise activities] over the years...the only thing that I see

results quickly from is CrossFit@.” FM24 stated, "When you start [CrossFit $\left.{ }^{\circ}\right]$, and you'll see a

dramatic change from when you first start to like two months." MT1 indicated that excitement

over these quickly-obtained results led to overuse risk behaviors:

Overuse does happen. It's like...kids and candy. They love it. They'll eat it all day, but it'll give them cavities, and it'll make them bounce off the walls and make your life a living hell until they calm down and fall asleep or something. These guys [CrossFit ${ }^{\circledR}$ members] come in. They'll be so excited [about the results]. They'll do all this work. They'll do all this work. They'll do all this work. They'll get injured. They'll get miserable about it. They'll stop coming in...That is where we start getting down the path of overuse: too much all the time... They have no idea what we have in store for them the rest of the week, but they decide to do something [extra workouts] on their own.

Because injured members "stop coming in", GO1 stated that injury of members went against his

business interest as some injured members discontinue their paid membership. Unfortunately, the desire for results could drive members to "push themselves recklessly and get hurt" (MM42) 
and engage in overuse injury risk behaviors. For example, MM29's desire to improve performance results affected his decision to persist despite pain: "If I have to do 60 kettle bell swings, and I'm on number 20 , I'll probably take a break. If I'm at number 50, I'll probably push through it [pain] to finish the 60 ...It'd be...how close I am to...target goal.” FM2 similarly opted to "push through" the pain when she was close to finishing a workout:

Tonight we were doing knees-to-elbow, and...my right shoulder is giving me problems. It always has, ever since I started CrossFit ${ }^{\circledR}$. The part where you put your knee up hurt my shoulder...I felt like a shooting pain here. I was just like, 'Let me just keep going. Workout's almost done. You've got like 30 seconds left,' so I kept going.

Thus, in pursuit of desired results, some CrossFit ${ }^{\circledR}$ members engaged in overuse risk behaviours (e.g., continuing exercise despite pain; doing more repetitions rather than resting).

Camaraderie. Members indicated that they valued camaraderie which embodied social aspects of CrossFit ${ }^{\circledR}$ such as "social interaction", "community", "like family", "encouraging", "welcoming", and "inclusive". One way in which this value was enacted was conversations. When the first author entered the gym, the cacophony of noise often resembled that of a restaurant due to the sound of laughing and chatter of numerous members assembled in the stretching areas and on the benches. During observations, some content of members' conversation was CrossFit ${ }^{\circledR}$-specific (e.g., impending workouts, pain, equipment, perceptions of trainers), but much was not (e.g., restaurants, sports, social plans, tv shows, life events, flirtatious comments). GO1 thought that the "shared experience of the intense workout" was a reason this form of camaraderie developed. MM32 explained further:

You have a natural affinity to people that are also doing CrossFit $®$ because pretty much they're the only ones that know how intense it is or how hard that particular day's workout was.... and that common experience I think leads to sort of a community sense of camaraderie... This is a crazy analogy, but there's a reason why Presidents of the United States, whether they're Republican or Democrat, you notice that after they leave the White House, they're all friends. Only they have been through what they've been 
through. Same thing with people in the military. There are certain activities that are these shared experiences that I think lead[s] to people liking each other.

Another interviewee demonstrated that the shared, intense experience led to "people liking each other". He initially disliked a new, "annoying" member, but "I love the guy now because...we've been doing this thing together, and we've experienced all the highs and the lows." Observations revealed another way in which camaraderie was enacted as members and trainers were often observed addressing each other by name. FM31 noted that she did not know the names of the instructors or other participants of group fitness classes she had taken at other gyms. A reason CrossFit ${ }^{\circledR}$ members knew each other’s names was regular attendance. In group fitness classes she took prior to CrossFit ${ }^{2}, \mathrm{FM} 2$ "rarely recognized a face because people were just random, and, but with CrossFit ${ }^{\circledR}$, people usually do it at the same time every day. You get familiar with who you're working out with.” MM32 came to enjoy this aspect:

I'm the least social person so the fact that I would enjoy it [social interaction in CrossFit $\AA]$ or kind of willingly participate in it is shocking to me...There's interaction with the athletes who are in the previous class, that are just kind of getting ready to leave, and you're coming in, so you get to see them. Then those that are in the class after yours, so you almost have like three groups of people that you kind of see on a regular basis, every day... and I get to have interaction with.

Aside from conversing and personal greetings, another way camaraderie was enacted was via encouragement of other members (e.g., applauding, cheering other members). According to FM12, members could be positively evaluated by other members when they encouraged others. She was "very impressed by the good people who encourage the people who are struggling". For some members, such as MM30, the outcome of encouragement was to increase effort: "I can think of multiple examples of when guys I'm directly competing with are encouraging me to move faster, move quicker, push harder". This effect of encouragement was observed multiple times, as members encouraged each other to "Keep going". For example, while climbing up a 
525 rope that was affixed to the gym's ceiling, MM21 stopped about halfway up, appearing stuck.

526 When MM20 called up to MM21, “Go, go, go!”, MM21 resumed climbing. However, the

527 trainers appeared aware of a need to temper excessive effort resulting from encouragement. In

528 one observation, MT4 was guiding FM14 through her first attempt at climbing up a rope. He

529 directed her to climb only to the third knot (i.e., halfway up). He did not want her to go all the

530 way up only to find she was too fatigued to return down safely. As FM14 climbed, a member

531 started cheering for FM14, saying "Go all the way [to the top]!”. MT4 countered in a light tone,

532 saying "The goal was three. Don't listen to your peers. They'll get you in trouble."

533 The value of camaraderie was relevant to overuse risk behaviors in two ways. First,

534 regular attendance and engagement in intense workouts were the ingredients for creating

535 camaraderie. Yet, by exercising excessively or despite pain in order to be with the people they

536 enjoyed being with, members risked overuse injury. Second, an outcome of verbal

537 encouragement was that members increased effort. Members can be susceptible to overuse

538 injury when they respond to encouragement with excessive effort or "keep going" despite pain.

539 Responses to Criticisms about the Occurrence of Injury in CrossFit ${ }^{\circledR}$ Activity

540 For the second research question, all interviewees indicated awareness of criticisms about

541 injury incurred in CrossFit $\AA$. They responded to these criticisms by (a) comparing various

542 dimensions in CrossFit ${ }^{\circledR}$ to other physical activities, and (b) denouncing the critics.

543 Comparing Dimensions to Other Contexts. In discussing criticisms, members did not

544 appear to perceive the occurrence of injury in CrossFit@ to be high. Members supported this

545 perception by comparing injury in CrossFit ${ }^{\circledR}$ to injury in other physical activity contexts such as

546 sport, everyday activities, and other forms of exercise. For example, FM12 indicated that the

547 risk of injury in CrossFit ${ }^{\circledR}$ was acceptable when compared to sports: 
Any sport has risks, has risk of injury. And, that's really, it's really our personal responsibility to know them and to take care of them...I do not in any way feel like it's CrossFit@'s fault, any more than it's NFL's [National Football League] fault that people get their like s*** knocked out of them at football games... I don't really understand all the finger-pointing at CrossFit®.

Some members, like FM31, pointed out that injury occurs during everyday activities: "It's not

CrossFit ${ }^{\circledR}$ that you can just hurt your back in. You can lift a box that's too heavy."

Other members emphasized aspects of injury which made them perceive CrossFit ${ }^{\circledR}$ to be superior to those contexts. Members perceived the frequency and severity of injuries incurred in CrossFit ${ }^{\circledR}$ to be less than that of injuries incurred during prior sport/exercise participation:

When I would run, I would be in a lot more pain, and I would either turn an ankle, or my knee would swell up. I would have all sorts more aches and pains and injuries than I've ever experienced at CrossFit ${ }^{\circledR}$.... I've had one injury in 20 months. Compared to previous injuries that I had doing other forms of exercise, I used to have a lot more. (MM32)

MM34 thought that the strength gained via CrossFit ${ }^{\circledR}$ participation made him less susceptible to injuries: "I think I've kind of built up my tendons and ligaments and scar tissue, and everything is just to the point where now I'm kind of adapted I guess." Further, members emphasized that injury prevention in CrossFit ${ }^{\circledR}$ gyms was better than other gyms because of the presence of trainers during workouts:

I know plenty of people who have injured themselves in a [traditional] gym because of improper form, and no one was there to show them how to properly do it... whereas in CrossFit ${ }^{\circledR}$, you do have that coach that's going to walk around, correct you, and be able to tell you what you did wrong, and to fix it so that you won't get injured. (FM24)

Members also indicated that CrossFit ${ }^{\circledR}$ was superior to other exercise contexts because members tended to modify workouts around pain and resolve injury rather than giving up and ceasing exercise due to injury. As MM1 stated, "CrossFit ${ }^{\circledR}$ will find your weakness, so a lot of people, they get their weakness exploited, and they look for the door. It takes a lot of patience to figure out a way around it." 
Denouncing Critics. Another prominent way in which members responded to criticisms about injury in CrossFit ${ }^{\circledR}$ activity was by denouncing critics for using a flawed rationale in their criticism. Some interviewees criticized critics for using extreme examples as a basis for negative perceptions of injuries in the CrossFit@ context:

It's the availability bias right? You hear people talk about, 'Well I did CrossFit $\AA$ for a week, but then I injured my back, and then I injured it twice more in that same month, so I quit CrossFit ${ }^{\circledR}$.' Those stories stick with you...People that join CrossFit ${ }^{\circledR}$ and don't have any issues probably don't talk daily about the fact that they don't have any injury issues, so it's easy to recall instances where you heard about someone getting injured or you saw someone getting injured. Standing in a class of six people and witnessing an injury means there were five other people that weren't injured. (MM42)

MT1, too, thought that false perceptions of CrossFit ${ }^{\circledR}$ 's high injury risk were based on extreme examples, such as when a member at another gym became paralyzed. When the member at the other gym dropped a bar, the bar landed on some plates that were lying on the floor, then bounced back and hit the member's spine, yet this is not a common occurrence in CrossFit ${ }^{\circledR}$ workouts nor exclusive to CrossFit@.

Some CrossFit ${ }^{\circledR}$ members criticized critics who demonized CrossFit ${ }^{\circledR}$ without taking into account the health and fitness benefits of exercise adherence. Before starting CrossFit@, MM1 was overweight and had not adhered to any physical activity consistently. Though he nursed a sore shoulder for 10 months during CrossFit ${ }^{\circledR}$ workouts, he weighed the sore shoulder against the benefits of CrossFit ${ }^{\circledR}$ membership which enabled him to adhere consistently so that he lost weight and perceived himself to be healthier. MM32 had tried many other exercise/sport programs but only sustained regular adherence in CrossFit@. Though he tweaked his back in CrossFit ${ }^{\circledR}$, CrossFit ${ }^{\circledR}$ was still worthwhile to him. As MM34 said, "If this is what I need to do to get in shape and be the best person that I can be, more power to me. I'll work out my way. You work out your way". 
Interviewees also negated critics' who had no direct experience with CrossFit@. FM31's boyfriend was "very worried about me doing it...he's afraid I'm going to hurt my back." However, "He’s never tried it [CrossFit@]." Rather than stopping CrossFit® due to his 609 concerns, she opted to not discuss CrossFit ${ }^{\circledR}$ with him: "I don't really talk about it with 610 him...because if we do bring it up, I don't really want to have an argument about it." When FM2 611 learned that students in exercise science programs at a nearby university were being taught that 612 CrossFit ${ }^{\circledR}$ was "bad”, she said, "you need to try it before you say anything else... you don’t 613 know what you're talking about...it's like trying to talk about cake when you've never tried 614 cake." MM36 also discredited critics who did not participate in CrossFit ${ }^{\circledR}:$ "[they] make it 615 sound like we do one-rep maxes 20 times... They don't know about scaling." In the CrossFit ${ }^{\circledR}$ 616 lexicon, scaling involves reducing workout quantities to amounts suited to the individual's 617 factors (e.g., ability level, injury). MM44 described his interactions with two physical therapists 618 who initially indicated disapproval of CrossFit ${ }^{\circledR}$. One told him, "You're going to hurt yourself. 619 You're going to mess your shoulder up. I'd never let my kids do it”. After interacting with him 620 more, they then told MM44, "You seem like the kind of guy who's going to take care of 621 yourself...if it hurts, stop. If you feel yourself going too far, take a break, but as long as you do 622 exercises... and rehab your shoulder on your own, you'll be fine". Thus, MM44 believed that 623 critics' negative perception of CrossFit ${ }^{\circledR}$ activities changed when they were exposed to an actual 624 CrossFit ${ }^{\circ}$ member. Finally, interviewees emphasized that CrossFit $®$ gyms differ on many 625 facets (e.g., trainer attentiveness/experience, workout programming). Thus, they discounted 626 general criticism of CrossFit@ that was not specific to the context at this gym. 


\section{Discussion}

In this study, we sought to identify values of group exercise participants relevant to overuse risk behaviors as well as their responses to criticisms about injury. Through thematic analysis, we identified three values (i.e., being hard core, achieving results, camaraderie) that were relevant to overuse risk behaviors. We also identified two prominent types of responses (i.e., compare dimensions of CrossFit ${ }^{\circledR}$ to other physical activities, denounce critics) of CrossFit ${ }^{\circledR}$ members to criticisms about injury in CrossFit ${ }^{\circledR}$ activity. Here, we discuss these findings in relation to constructs of the social identity approach: Social identity content and social threats.

\section{Social Identity Content}

The three values identified in this study - being hard core, achieving results, camaraderie - were interpreted to represent the social identity content of the group. That is, members perceived these values to be reasons for being members of this group instead of other physical activity groups; commonly endorsed by members; exemplified by highly-regarded members; and a means for being perceived more positively by other members. This is not to say that these values and associated behaviors are unique to this group; it might be that members of other social identity groups endorse similar values (e.g., military members endorse camaraderie). Nor do we imply that these members did not experience these values in other contexts (e.g., camaraderie felt in previous sport participation). Rather, these CrossFit ${ }^{\circledR}$ members indicated that these values, and the behaviors they used to enact the social identity content, were unique to their membership in CrossFit@. This is demonstrated by CrossFit ${ }^{\circledR}$ members who expressed that they had not engaged in some behaviors to the same degree in other physical activity contexts (e.g., a member who had not engaged in the same intensity in biking; a member's attendance in previous 
650 sport/exercise contexts was sporadic; a member did not know the names of people in other, non-

651 CrossFit ${ }^{\circ}$ fitness classes). Only when they became members of this social identity group — this

652 CrossFit gym - were these values central to shared social identity such that members engaged in

653 associated behaviors to a higher intensity, frequency, or level not experienced previously. When

654 behaviors stemming from the group's social identity content constituted overuse risk behaviors,

655 this group-based psychological factor was shown to be relevant to overuse injury. This finding is

656 unique given that individual (e.g., Type A personality) and inter-personal (e.g., pressure from

657 coaches to train despite pain) factors were the focus or findings of previous overuse injury

658 research (e.g., Ekenman et al., 2001; Russell \& Wiese-Bjornstal, 2015; Tranaeus et al., 2014).

The value for being hard core was enacted, in part, by members who attended high-

660 intensity workouts more than three times per week and, in some instances, with less than 24

661 hours between workouts, which puts members at risk for overuse, orthopedic injuries (ACSM,

662 2014; Drum et al., 2014). For some CrossFit ${ }^{\circledR}$ members, the choice to engage frequently in

663 high-intensity workouts was due in part to enjoyment of intense workouts. This is aligned with

664 researchers who found that people engaged in and/or preferred high-intensity physical activity in

665 part because of the pleasure they derived from engaging in high-intensity physical activity

666 (Ekkekakis et al., 2011). However, these CrossFit ${ }^{\circledR}$ members indicated more reasons for

667 engaging in high-intensity workouts. Completing difficult, high-intensity workouts, consisting

668 of "things that I didn't think I could do", enabled them to earn a "badge of honor" and yielded a

669 higher confidence in abilities. CrossFit ${ }^{\circledR}$ members in other studies (e.g., Bailey et al., 2017)

670 similarly expressed a sense of accomplishment from engaging in high-intensity workouts. One

671 interpretation is that $\mathrm{CrossFit}{ }^{\circledR}$ members who gained confidence in their abilities by participating

672 in the group's activity - high-intensity workouts - also experienced an increase in their self- 
673 competence which is an aspect of global self-esteem (i.e., positive evaluation of one's self based 674 on one's abilities; Tafarodi \& Swann, 2001). The social identity content of being hard core was

675 also enacted by withholding pain reports (e.g., not whining). By doing so, members could

676 prevent negative evaluations by group members and leaders. Previous studies of overuse injury

677 revealed that athletes in sport contexts likewise tended to withhold pain reports because they

678 feared they would be negatively evaluated by team members and leaders which could affect their 679 sport careers/livelihood (e.g., team selection, winning, professional athletes' paychecks;

680 Tranaeus et al., 2014; Turner et al., 2002). The current study was unique, demonstrating that 681 members of a group exercise program exhibited the same tendencies as athletes, though careers and livelihood were not at stake. Fear of negative evaluation is a commonality in both contexts.

In this study, we observed a desire for performance- and/or appearance-related results.

684 This desire was not captured in previous studies of CrossFit ${ }^{\circledR}$ members who primarily expressed 685 desires to be healthy, be fit, and learn new skills (Bailey et al., 2017) which do not intuitively 686 contribute to overuse risk behaviors. Here, group members' desire for results was shown to be 687 relevant to overuse risk behaviors. As indicated by a trainer, the desire for results induced 688 members to do more than the workouts prescribed by trainers. These statements mirrored the 689 findings of Montalvo and colleagues (2017) that CrossFit@ members who did extra physical 690 training outside of CrossFit@ workouts were at higher risk for injury than those who only did 691 CrossFit ${ }^{\circledR}$ workouts. The current findings indicate that this social identity content — the group 692 members' value for results — was an underlying reason for engaging in the extra training that 693 underlies overuse injuries. Some findings pertaining to CrossFit ${ }^{\circledR}$ members' camaraderie was not exclusive to this 695 study. Other researchers (e.g., Bailey et al., 2017) have also found that the shared experience of 
high-intensity workouts is viewed as a source of CrossFit ${ }^{\circledR}$ members' camaraderie, and that encouragement between members is a common behaviour in the CrossFit ${ }^{\circledR}$ context. However, a novel finding was that a way in which camaraderie is enacted - through verbal encouragementmay induce higher effort. These findings in a naturalistic setting augment those of laboratory settings in which researchers provided verbal encouragement to participants who then tended to respond with increased effort (e.g., Moffatt et al., 1994). Together, these findings are suggestive that verbal encouragement used to enact camaraderie may inadvertently be relevant to overuse injury when members respond to verbal encouragement with excessive effort.

Throughout the findings related to social identity content, members were able to obtain positive evaluations or avert negative evaluations of group members and/or leaders when behaviors were aligned with social identity content. As illustrated by the member who initially found another member annoying, completing high-intensity workouts enabled the 'annoying member' to eventually be liked and accepted. Moreover, participants admired —or were admired by - fellow Crossfit ${ }^{\circledR}$ members who enacted the social identity content via other behaviors such as regular attendance, attendance despite adversity (e.g., recovering from illness), performing well on a specific activity even if they were not typically one of the best performers, and encouraging a struggling member. Thus, the behaviors used to enact social identity content gave CrossFit ${ }^{\circledR}$ members a means for being respected and/or liked by other group members. It could be that members of the group engage in these behaviors because doing so enables them to experience enhanced self-liking, a form of global self-esteem that relies in part on the social judgements of one's self conveyed by others (Tafarodi \& Swann, 2001). Altogether enjoyment and gains in self-esteem, be it in the form of self-competence or self-liking, appear to be positive outcomes of adhering to the social identity content of this group. However, the overarching 
719

720

721

722

723

724

725

726

727

728

729

730

731

732

733

734

735

736

737

738

739

740

741

concern is this: The behaviors that group members used to enact social identity content may

enable them to derive enjoyment and self-esteem from group membership, yet the same

behaviors put members at higher risk for overuse injury occurrence and severity.

\section{Social Threats}

In responding to criticisms about injury, interviewees compared CrossFit ${ }^{\circledR}$ to other

physical activity contexts on various dimensions. Members asserted that the injury occurrence in CrossFit ${ }^{\circledR}$ was equivalent to or lower than that in other physical activities, whilst the severity of injuries incurred in CrossFit ${ }^{\circledR}$ was lower. They pointed out that the health benefits of CrossFit ${ }^{\circledR}$ membership were greater than that of other contexts and, as such, outweighed the drawback of injuries. Members also implied superiority of the CrossFit ${ }^{\circledR}$ context in that trainers were on hand to prevent injury occurrence, in contrast to gyms with no such presence. This assertion was supported by previous studies which indicated that the presence of CrossFit ${ }^{\circledR}$ trainers was related to lower injury rates (Weisenthal et al., 2014). In this study, specific ways in which trainers can be integral to injury-prevention efforts were revealed: Trainers modified workouts when members expressed pain; guided members to temper their effort when encouraged by other members to try harder; and reduced fear of negative evaluation by soliciting pain reports and expressing their own pain. Also, participants viewed CrossFit@ members as superior to participants in other physical activity programs in that they handled their injuries well instead of ceasing exercise when injuries occurred. Further, the CrossFit@ program was viewed as superior in that it strengthened members so that their injury susceptibility decreased.

According to the social identity approach, through positively distinguishing one's group from other groups, being a member of a group increases positive evaluations of one's own worth (i.e., self-esteem; Jetten et al., 2017). When an aspect of a group is negatively evaluated by 
742 others, the valued source of self-esteem is threatened (i.e., social threat). In response, group

743 members may engage in social creativity (Haslam \& Reicher, 2006). Social creativity involves

744 maintaining a positive social identity through developing the group's social identity content such

745 that the group is seen as superior to other groups (i.e., achieves positive distinctiveness). For

746 example, a sport team on a losing streak cannot achieve positive distinctiveness on the dimension

747 of winning (outcome). Therefore, members may assert the teams' superiority on a dimension

748 other than outcome, such as sportsmanship or creativity. They may claim, for example, 'that

749 winning isn't everything; more important is how you play the game and playing fairly.' In this

750 sense, CrossFit ${ }^{\circledR}$ members' responses to injury criticisms resembled social creativity such that

751 injury occurrence wasn't everything; more important was how well members handled the

752 injuries, the effort they put into prevention, the health benefits, or the strength they gained.

The second pattern observed in CrossFit ${ }^{\circledR}$ members' responses to injury criticisms

754 involved denouncing features of those who criticize CrossFit ${ }^{\circledR}$. This was done by dismissing

755 critics whose criticisms were products of bias from extreme examples of injury, incomplete

756 information, lack of personal experience with CrossFit@, or lack of specificity to individual

757 CrossFit ${ }^{\circledR}$ contexts. A possible interpretation of this pattern is another type of response to social

758 threats referred to as polarization (Brown \& Ross, 1992). Polarization involves members’

759 defense of a social identity group by discounting the information critics provide. Of note,

760 instead of agreeing with critics, or adhering to advice and recommendations of critics, members

761 tend to react to criticisms by becoming more ensconced in their beliefs as well as a decreased

762 desire to leave the group and an increased antipathy towards other groups (Brown \& Ross, 1982;

763 Hogg \& Reid, 2006). Altogether, these findings demonstrated that criticisms about injury-even

764 when the critics were exercise and medical experts-did not induce members to perceive injury 
as a problem, reflect on how to prevent injury, or change their injury-related behaviors because these criticisms did not come from members of their own group.

Having identified some underlying values associated with a CrossFit group together with associated (negative) behaviors, future research might examine how social identity content can be modified by group leaders to change resultant negative behaviors (Haslam et al., 2011). Injury-prevention interventions in CrossFit@ contexts may consist of leaders emphasizing values that are not enacted by overuse risk behaviors. Doing so can change members' perceptions of group values from, for example, "We are hard core" to "We are smart about injury prevention". Likewise, the basis for positive evaluations could be changed. For example, CrossFit ${ }^{\circledR}$ members may be more apt to work out at a more moderate intensity, rest more, or decrease effort/participation/report pain when they feel pain if they are praised for being injury-free for 20 months instead of only being praised for attending 20 months or for visible results. The findings about social threats suggest that injury-prevention recommendations may be more effective when implemented or communicated by CrossFit ${ }^{\circledR}$ leaders or members rather than experts who are not members. For example, rather than experts critiquing the form of CrossFit@ members, group leaders may teach members to word verbal encouragement to emphasize technique (e.g., "Keep good form!") instead of excessive effort (e.g., "Keep going!”).

Despite the value of these practical implications, we acknowledge the study's limitations. We limited the scope of psychological factors to identification of group values. Other factors may have greater bearing on overuse injury occurrence in this context. Also, we opted to focus on the utility of the social identity approach which led to us interpret data in relation to social identity constructs (e.g., social identity content, social creativity, polarization). Other theoretical approaches may reveal different, viable interpretations of participants' experiences and data. For 
example, impression management theory could yield insight into findings pertaining to fear of negative evaluation beyond negative evaluation by members of one's social identity group. Further, our use of qualitative methodology and sampling method limited the generalizability in that these findings are specific to one CrossFit@ gym.

However, we considered the results in terms of other forms of generalizability applicable to qualitative research methods (Smith, 2018), which could be viewed as a strength of this project. Naturalistic generalizability involved presenting details of participants' words and behaviors such that readers with no exposure to CrossFit@ gyms, CrossFit ${ }^{\circledR}$ lexicon, social identity, or injury could understand these results within their own personal life experiences (e.g., being amazed upon learning one can complete a difficult task; a gym where patrons do not talk to each other or know each other's names). Via inferential transferability, people not involved in this specific CrossFit ${ }^{\circledR}$ setting may consider adopting a new practice due to what was learned in this project (e.g., other exercise group leaders may guide exercisers to temper effort when encouraged by others to try harder or solicit pain reports). Analytical generalization was achieved by generalizing results to an established concept or theory (e.g., discussing results in relation to social identity constructs of social creativity and polarization).

This study is one of the first to examine social identity constructs in relation to injury, psychological factors of overuse injury in exercise contexts, and psychological factors underlying injury in a CrossFit@ context. It provided empirical support for the proposition that the social identity approach is an applicable theoretical framework for examination of injury. Overall, this study is critical in understanding why exercisers engage in injury-inducing behaviors and how membership in social identity groups plays a role.

\section{References}


811 American College of Sports Medicine (2014). ACSM's guidelines for exercise testing and prescription. Philadelphia, PA: Wolter Kluwere/Lippincott, Williams \& Wilkins.

Bailey, B., Benson, A. J., \& Bruner, M. W. (2017). Investigating the organisational culture of CrossFit. International Journal of Sport and Exercise Psychology. https://doi.org/10.1080/1612197X.2017.1329223

Braun, V., \& Clark, V. (2006). Using thematic analysis in psychology. Qualitative Research in Psychology, 3(2), 77-101. doi: 10.1191/1478088706qp063oa

Brown, R. J., \& Ross, G. F. (1982). The battle for acceptance: An investigation into the dynamics of intergroup behaviour. In H. Tajfel (Ed.), Social identity and intergroup relations (pp. 15-40). Cambridge, UK: Cambridge University Press.

Cavallerio, F., Wadey, R., \& Wagstaff, C. R. D. (2016). Understanding overuse injuries in rhythmic gymnastics: A 12-month ethnographic study. Psychology of Sport and Exercise, 25, 100-109. https://doi.org/10.1016/j.psychsport.2016.05.002

Chan, D. K. C., Lentillon-Kaestner, V., Dimmock, J. A., Hardcastle, S. J., Donovan, R. J., \& Hagger, M. S. (2014). Athlete's beliefs about and attitudes towards taking banned performance-enhancing substances: A qualitative study. Sport, Exercise, and Performance Psychology, 3(4), 241-257. https://doi.org/10.1037/spy0000019

CrossFit. (n.d.) Affiliate map. Retrieved January 20, 2020, from https://map.crossfit.com/ Diamond, D. (2015, May). Is CrossFit ${ }^{\circledR}$ safe? What 60 Minutes didn't tell you. Forbes. https://www.forbes.com/sites/dandiamond/2015/05/11/is-crossfit-good-for-you-what-60minutes-didnt-say/\#3b515ea2508c

Drum, S. N., Bellovary, B. N., Jensen, R. L., Moore, M. T., \& Donath, L. (2017). Perceived demands and post-exercise physical dysfunction in CrossFit ${ }^{\circledR}$ compared to an ACSM 

based training session. The Journal of Sports Medicine and Physical Fitness, 57(5), 604609. doi: $10.23736 / \mathrm{S} 0022-4707.16 .06243-5$

Ekenman, I., Hassmen, P., Koivula, N., Rolf, C., \& Fellander-Tsai, L. (2001). Stress fractures of the tibia: Can personality traits help us detect the injury-prone athlete? Scandinavian Journal of Medicine \& Science in Sports, 11, 87-95. doi: 10.1034/j.16000838.2001.011002087.x

Ekkekakis, P., Parfitt, G., \& Petruzzello, S. J. (2011). The pleasure and displeasure people feel when they exercise at different intensities: Decennial update and progress towards a tripartite rationale for exercise intensity prescription. Sports Medicine, 41(8), 641-671. doi: 10.2165/11590680-000000000-00000

Evans, A. L., Slater, M. J., Coffee, P., \& Barker, J. B. (2016). Pulling the group together: The role of the social identity approach. In Thelwell, R., Harwood, C., \& Greenlees, I. (Eds.). The psychology of sports coaching: Research and practice. (pp. 265-280). Routledge.

Jetten, J., Haslam, S. A., Cruwys, T., Greenaway, K. H., Haslam, C., \& Steffens, N. K. (2017). Advancing the social identity approach to health and well-being: Progressing the social cure research agenda. European Journal of Social Psychology, 47, 789-802. https://doi.org/10.1002/ejsp.2333

Haslam, S. A., \& Reicher, S. (2006). Stressing the group: Social identity and the unfolding dynamics of responses to stress. Journal of Applied Psychology, 91, 1037-1052. DOI: 10.1037/0021-9010.91.5.1037

Haslam, S. A., Reicher, S. D., \& Platow, M. J. (2011). The new psychology of leadership: Identity, influence and power. East Sussex, UK: Psychology Press. 
Hennink, M. M., Kaiser, B. N., \& Marconi, V. C. (2017). Code saturation versus meaning saturation: How many interviews are enough? Qualitative Health Research, 27(4), 591608. https://doi.org/10.1177/1049732316665344

Hings, R. F., Wagstaff, C. R. D., Anderson, V., Gilmore, S., \& Thelwell, R. C. (2020). Better preparing sports psychologists for the demands of applied practice: The emotional labor training gap. Journal of Applied Sport Psychology, 32(4), 335-356. https://doi.org/10.1080/10413200.2018.1560373

Hogg, M. A., \& Reid, S. A. (2006). Social identity, self-categorization, and the communication of group norms. Communication Theory, 16, 7-30. https://doi.org/10.1111/j.14682885.2006.00003.x

Johnson, U., Tranaeus, U., \& Ivarsson, A. (2014). Current status and future challenges in psychological research of sport injury prediction and prevention: A methodological perspective. Revista de Psicologia del Deporte, 23(2), 401-409.

Kaushik, V., \& Walsh, C. A. (2019). Pragmatism as a research paradigm and its implications for social work research. Social Sciences, 8(255), 1-17. https://doi.org/10.3390/socsci8090255

Klimek, C., Ashbeck, C., Brook, A. J., \& Durall, C. (2018). Are injuries more common with CrossFit training than other forms of exercise? Journal of Sport Rehabilitation, 27, 295299. doi: 10.1123/jsr.2016-0040

Launay, F. (2015). Sports-related overuse injuries in children. Orthopaedics \& Traumatology: Surgery \& Research, 101, S139-S147. doi: 10.1016/j.otsr.2014.06.030 
877 Livingstone, A. G., \& McCafferty, S. (2015). Explaining reactions to normative information

878

879

880

881

882

883

884

885

886

887

888

889

890

891

892

893

894

895

896

897

898

899

about alcohol consumption: A test of an extended social identity model. International Journal of Drug Policy, 26(2015), 388-395. doi: 10.106/j.drugpo.2014.10.005

Long, N., Readdy, T., \& Raabe, J. (2014). What motivates firefighters to exercise? A mixedmethods investigation of self-determination theory constructs and exercise behavior. Sport, Exercise and Performance Psychology, 3(3), 203-218. https://doi.org/10.1037/spy0000012

Maffulli, N., Longo, U. G., Gougoulias, N., Caine, D., \& Denaro, V. (2010). Sport injuries: A review of outcomes. British Medical Bulletin, 97, 47-80. https://doi.org/10.1093/bmb/ldq026

Moffatt, R. J., Chitwood, L .F., \& Biggerstaff, K. D. (1994). The influence of verbal encouragement during assessment of maximal oxygen uptake. The Journal of Sports Medicine and Physical Fitness 34(1), 45-49.

Montalvo, A. M., Shaefer, H., Rodriguez, B., Li, T., Epnere, K., \& Myer, G. D. (2017). Retrospective injury epidemiology and risk factors for injury in CrossFit. Journal of Sports Science and Medicine, 16, 53-59.

Morgan, D. L. (2014). Pragmatism as a paradigm for social research. Qualitative Inquiry, 20(8). 1045-1053. https://doi.org/10.1177/1077800413513733

Morse, J. (2019). The changing face of qualitative inquiry. International Journal of Qualitative Methods, 19, 1-7. https://doi.org/10.1177/1609406920909938

Russell, H. C., \& Wiese-Bjornstal, D. M. (2015). Narratives of psychosocial response to microtrauma injury among long-distance runners. Sports, 3, 159-177. https://doi.org/10.3390/sports3030159 
900 901

Smith, B. (2018). Generalizability in qualitative research: Misunderstandings, opportunities and recommendations for the sport and exercise science. Qualitative Research in Sport, Exercise and Health, 10(1), 137-149. https://doi.org/10.1080/2159676X.2017.1393221

Tracy, S. J. (2010). Qualitative quality: Eight "Big Tent" criteria for excellent qualitative research. Qualitative Inquiry, 16(10), 837-851. https://doi.org/10.1177/1077800410383121

Tranaeus, U., Johnson, U., Engstrom, B., Skillgate, E., \& Werner, S. (2014). Psychological antecedents of overuse injuries in Swedish elite floorball players. Athletic Insight, 6(2), 155-172.

Tafarodi, R. W., \& Swann Jr, W. B. (2001). Two-dimensional self-esteem: Theory and measurement. Personality and Individual Differences, 31(5), 653-673. https://doi.org/10.1016/S0191-8869(00)00169-0

Turner, A., Barlow, J., \& Ilberry, B. (2002). Play hurt, live hurt: Living with and managing osteoarthritis from the perspective of ex-professional footballers. Journal of Health Psychology, 7(3), 285-301. https://doi.org/10.1177/1359105302007003222

Turner, J. C., Hogg, M. A., Oakes, P. J., Reicher, S. D., \& Wetherell, M. S. (1987). Rediscovering the social group: A self-categorization theory. Oxford, UK: Basil Blackwell.

Weisenthal, B. M., Beck, C. A., Maloney, M. D., DeHaven, K. E. \& Giordano, B. D. (2014). Injury rate and patterns among CrossFit athletes. Orthopedic Journal of Sports Medicine, 2(4), 1-7. https://doi.org/10.1177/2325967114531177 
921 Wilder, R. P., \& Sethi, S. (2004). Overuse injuries: Tendinopathies, stress fractures, compartment syndrome, and shin splints. Clinics in Sports Medicine, 23, 56-81.

923 https://doi.org/10.1016/S0278-5919(03)00085-1 


\section{Characteristics of Interviewees}

\begin{tabular}{|c|c|c|c|c|c|c|}
\hline Interviewee & Age & $\begin{array}{c}\text { Membership } \\
\text { Duration } \\
\text { (Months) }\end{array}$ & $\begin{array}{c}\text { Frequency } \\
\text { (Times per } \\
\text { Week) } \\
\end{array}$ & Competitive Status & Ability Level & $\begin{array}{c}\text { Interview } \\
\text { Duration } \\
\text { (Minutes) }\end{array}$ \\
\hline FM12 & 43 & 13 & $4-5$ & 1 competition for beginners & Meets some & 56.20 \\
\hline MM43 & 34 & 6 & 4 & Attends workouts & Often last in workouts & 68.33 \\
\hline FM2 & 33 & 60 & $3-4$ & Attends workouts & Meets most & 60.42 \\
\hline MM42 & 33 & 65 & 3 & Attends workouts & Meets some & 52.52 \\
\hline MM29 & 32 & 6 & 4 & Attends workouts & Does not meet & 93.68 \\
\hline FM24 & 20 & 42 & $4-5$ & 2 competitions & Meets most & 80.55 \\
\hline MM44 & 25 & 8 & $4-6$ & Intends to compete & Always meets & 49.97 \\
\hline FM31 & 28 & 48 & 2 & Attends workouts & Meets some & 74.62 \\
\hline MT1 & 25 & 41 & 7 & Competes in CrossFit@ Games & One of best males at this gym & 80.58 \\
\hline MM34 & 48 & 41 & 3 & Attends workouts & Meets some & 71.20 \\
\hline GO1 & 52 & 78 & & Attends workouts & Meets some & 142.62 \\
\hline MM1 & 34 & 48 & $3-5$ & Attends workouts & Meets some & 73.65 \\
\hline MM32 & 48 & 20 & 5 & Attends workouts & Meets most & 83.13 \\
\hline MM30 & 27 & 7 & $5-6$ & Intends to compete & One of best males at this gym & 67.38 \\
\hline
\end{tabular}

927 Notes. Additional information about participants is not presented to preserve anonymity. Ability level refers to participants' ability to

928 meet assigned quantities in workouts (e.g., amount of weight or repetitions). 